\title{
Uma abordagem sobre o tempo de(para) na ciência e academia
}

\section{Emília Rodrigues Araújo ${ }^{1}$}

\begin{abstract}
Resumo: O texto tem como propósito apresentar, de forma sucinta, as abordagens sociológicas sobre o tempo e a temporalidade nos mundos da ciência e da academia. Nesse sentido, procura mostrar quais são as principais contribuições dessa problematização para o desenho e implementação de políticas nas áreas da ciência e do trabalho académico. Sustentado em informação recolhida com recurso a entrevistas e observação realizadas em Portugal em vários momentos, o texto contribui para evidenciar as principais formas de revelação das experiências temporais dos próprios investigadores docentes e não docentes nos contextos das instituições de ensino superior.
\end{abstract}

Palavras-Chave: Tempo, temporalidade, academia, ciência.

\begin{abstract}
The purpose of this paper is to present briefly the main sociological approaches to time and temporality in the worlds of science and academia. In this sense, the text attempts to show what are the main contributions of this problematization for the design and implementation of policies in the areas of science and academic work. Grounded on information collected using interviews and observation carried out in Portugal the text highlights the main types of time experiences within the context of higher education institutions.
\end{abstract}

Keywords: Time, temporality, academy, science.

\section{Introdução}

Neste texto apresentamos uma proposta de quadro conceptual adequado à análise e entendimento do tempo e da temporalidade nos mundos da ciência e da academia. Entendemo-los enquanto elementos centrais para a compreensão dos modos de funcionamento desses dois mundos. Assumimos, também, que a discussão em seu redor permitirá contribuir para o debate sobre a qualidade das decisões e práticas quotidianas em tais contextos.

\footnotetext{
1 Docente no Departamento de Sociologia, Instituto de Ciências Sociais da Universidade do Minho. Investigadora do Centro de Estudos de Comunicação e Sociedade, da mesma Universidade (era@ics.uminho.pt).
} 
É um facto que o tempo em contexto académico, envolvendo a ciência e o ensino superior, tem sido objeto de trabalhos de investigação em períodos mais recentes (Ylijoki, 2010, 2013). No entanto, apesar da sua centralidade, tempo e temporalidade constituem-se como realidades naturalizadas, tomadas como garantidas e, por norma, apenas tidas como componentes dos fenómenos ou práticas que oferecem um nível mais amplo de objetivação. Argumenta-se, nesse sentido, ser importante produzir um olhar consistente sobre a importância do tempo e da temporalidade na ciência e no ensino superior. A principal assunção que seguimos determina que a desconstrução dessas naturalizações trará modos mais coerentes de apreensão e de ação sobre as realidades que atravessam os mais diversos processos implicados nas temporalidades da ciência e da academia.

Com efeito, a naturalização a que são relegados tempo e temporalidade deve-se ao facto de os atores envolvidos nos mais diversos graus e cargos na academia e na ciência estarem focados sobre a dimensão quantificável do tempo e, além disso, tenderem a assumir como inevitável o regime de tempo que impera nas organizações e na atividade científica e académica. Uma dimensão traduzível em percentagens de dedicação a tarefas, prazos, horários de trabalho, pontualidade, assim como a outras formas de disciplina do tempo. Talvez paradoxalmente, está ainda associada a esta naturalização a ideia sobre o caráter "necessariamente" desorganizado do tempo nos universos quotidianos das organizações de ciência e ensino. Desorganização que, sendo motivada e causa de colisão de tempos e de escalas de tempo (Ylijoki, 2010,2013), deriva tanto da intensificação de exigências e de atribuições, como da ausência de conhecimento, reflexão e planeamento do tempo (expresso, por exemplo, na sobreposição de prazos, alterações constantes de políticas e procedimentos, entre muitos outros).

Certo é que, apesar de o tempo e a temporalidade na academia e na investigação se constituírem como um assunto de menor projeção em contexto do debate e espaço públicos (na duração e processo), ganham relevo nas margens das discussões que se fazem, justamente, sobre ciência, ensino superior, tecnologia ou inovação na Europa e, especialmente, em Portugal.

Regulamentos, procedimentos, conferências, debates acerca da ciência e o ensino superior em Portugal tem sido caraterizados pelas manifestações dos atores investigadores docentes e não docentes - sobre o tempo: o tempo e as velocidades dos países centrais versus periféricos; o tempo do capital e do ensino; o tempo dos 
resultados e o tempo dos processos de pesquisa e aprendizagem; o tempo que há para o planeamento participado de políticas; o tempo da antecipação de avaliações e monitorias; o tempo que há para a proposição de projetos e submissão de candidaturas; o tempo estratégico para a tomada de decisão; o tempo para a preparação e avaliação individual; as desigualdades de tempo e a importância do dinheiro na troca de tempo e externalização de atividades; o tempo-projeto; o tempo da implementação de políticas e produção de impactos; o tempo da pesquisa e da investigação; o tempo para pensar; o tempo do investigador; a sincronia de ritmos; o tempo para investigar e para pensar; o tempo da aprendizagem e da docência; o controlo e a disciplina do tempo, a organização do tempo e o reconhecimento do tempo do(s) outro(s); o tempo estratificado e assim continuaríamos a elucidar sobre a infinidade de tempos com que se confronta e no fundo de se se faz a academia, o ensino, a ciência.

Podemos mencionar, ainda, várias das mudanças mais objetiváveis, mas não menos articuladas ou pensadas, que estão em curso e que respeitam claramente aos regimes de tempo. Essas passam pelas normalizações das durações dos tempos de trabalho dos investigadores expressas na necessidade de ponto e outros sistemas de controlo de entradas e saídas do mesmo espaço físico, entre outras formas de "gestão" e controlo do tempo.

De facto, é amplo o leque de problemáticas que podemos identificar relacionadas com as dimensões temporais da prática social. São também múltiplas as escalas e os níveis a que se podem tratar cada uma destas práticas, incluindo os horizontes temporais para onde se projetam as práticas, as frustrações e as orientações das sociedades no presente. Centramo-nos, para efeito deste texto, numa tentativa de construção introdutória ao estudo do tempo em contexto académico e de investigação, debruçando-nos sobre a exploração de três níveis principais de relevância do tempo: o tempo e os contextos organizacionais; e o tempo e as experiências subjetivas dos investigadores docentes e o tempo e a política científica.

Inclui-se informação recolhida em vários momentos pela autora seguindo um procedimento metodológico etnográfico, com recurso a análise de documentos e entrevistas levadas a cabo junto de investigadores a desempenhar atividade profissional em universidades e centros de investigação, parte dos quais envolvidos em atividades de docência no ensino superior. 
Assim, o texto começa com algumas das principais teses apresentadas por autores que trabalharam estas dimensões, noutros contextos geográficos, propondo-se, depois, uma problematização integrada com a informação recolhida para o contexto português. Terminamos com uma síntese sobre as principais contribuições do debate e discussão sobre o tempo para a política científica e formas de organização do tempo nos universos académicos e científicos. As conclusões de estudos empíricos realizados noutros contextos coincidem largamente com a informação que recolhemos. Porque é nosso intento centrar-nos nos elementos mais comuns da experiencia e narrativa do tempo, a análise conjunta das principais teses existentes sobre o tempo e a temporalidade na ciência apresenta-se mais adequada. Entre outras, contribui para a construção de uma abordagem mais estrutural do tempo nos campos sob análise.

\section{Problemática do Tempo para (na) Ciência e Academia}

As abordagens sobre tempo, ciência e academia estão focadas sobre três temáticas:

- $\quad$ Experiência subjetiva do tempo por parte dos investigadores (docentes e não docentes);

- $\quad$ Tempo do (no) processo de investigação;

- Horizontes temporais inscritos na própria práxis académica, isto é, um tipo de temporalidade estrutural veiculada e objeto de performance discursiva.

\section{Experiências do Tempo na Ciência e Academia}

A academia e a ciência constituíram-se como mundos "à parte" do conjunto social global das instituições, apresentando-se, inclusivamente, como espaços em que os objetos, resultados e impactos do trabalho que, em termos de importância, se sobrepõem às questões do espaço ou do tempo em que se desenrolam (ou de que necessitariam para se desenvolverem). Ora, Noonan (2015) considera estar-se num ponto de viragem no que respeita ao modo como o tempo é valorizado e usado nos contextos académicos. $\mathrm{O}$ foco da sua análise é a situação no Canadá, mas podia ser a de muitos outros países, incluindo Portugal.

Noonan (2015) discute, de algum modo, a fenomenologia do quotidiano-padrão do/a académico/cientista na atualidade: preocupado/a, ora com os indicadores de produção, ora com a necessidade de procurar alunos, financiamento e outros recursos. 
Os contextos de trabalho são marcados por uma profunda guerra semiótica dos tempos e das durações, refletida na ansiedade de publicação de resultados nas revistas científicas mais cotadas, na observação e controlo dos usos do tempo, assim como nas estratégias de separação e dedicação do tempo a tarefas administrativas, de docência e investigação.

Muller (2014, s/p), conclui que o que mais carateriza as narrativas dos cientistas pós doutorandos que entrevistou é a sensação de "estar permanentemente numa corrida competitiva que requer um ritmo cada vez mais acelerado, assim como um foco sobre o sucesso individual". Falando de contextos marcados por fortes discrepâncias de tempo e de autonomia de tempo entre os investigadores situados a níveis hierárquicos e situação de carreira distintos, alguns autores chamam a atenção para as questões da descontinuidade das práticas profissionais dos investigadores, assim como das transformações nas identidades individuais, moldadas aos próprios constrangimentos temporais impostos sobre si (Aït Ali e Rouch, 2013). A conciliação da vida entre contextos de atividade profissional e contextos privados e familiares surge evidenciada por outras investigações focadas, principalmente, em categorias menos abrangidas pelos contratos de longa duração.

Em resumo, os autores apontam no sentido da convivência dilemática entre o uso de metodologias participativas que procuram envolver os investigadores nas tomadas de decisão e a progressiva opacidade do tempo cujos resultados são menos imediatos. Isto é, defendem existir uma crescente redução dos tempos formalmente atribuídos a trabalho de orientação, tutoria, preparação e controlo administrativo de projetos e um aumento da quantidade de tempo diretamente (ou mais) ao dispor de controlo, através de sumários, presenças, etc.

\section{O Tempo - Estrutura ou Horizontes Temporais}

Tal como afirma Vostal (2013), o tempo precisa ser considerado na sua materialidade, como uma variável constituinte do quotidiano académico e científico e, simultaneamente, como eixo da estrutura que sustém os sistemas científicos no tempo, enquanto sistemas autopoiéticos. Dito de outro modo, as instituições e os processos movem-se na base de tempos e temporalidades de caráter longo e macro estrutural que condicionam os tempos organizacionais e individuais. 
O enquadramento dado pelos autores às questões do tempo na investigação e para a investigação inclui muito particularmente as análises mais globais realizadas por autores críticos da globalização da sociedade do conhecimento e também dos processos macro globais que tomam curso nessa sociedade. Destaque-se, no presente, a influência da abordagem de Rosa (2010). Este autor explica três dimensões centrais da "aceleração" na contemporaneidade. A primeira é a aceleração tecnológica que implica mudanças nos modos de recolha e troca de informação. A segunda é a aceleração da mudança social nos mais diversos contextos, implicando respostas mais rápidas (o que significa menos tempo para a decisão). A terceira dá conta da aceleração do ritmo de vida, expressa pelo avolumar de atividades que podem acontecer no mesmo intervalo de tempo. Rosa (2010) enceta todo um debate acerca da importância das estruturas macro global de tempo que oferece, além de outros, alguns insights pertinentes sobre as perceções e experiência psicológicas do tempo. Neste contexto, Clegg (2010) propõe e demonstra a vigência, ao nível do ensino superior e ciência, de uma temporalidade excessivamente orientada para o futuro, para o discurso e prática da excelência, do conhecimento de fronteira, da empregabilidade, da preparação e antecipação de projetos e escolhas. No mesmo artigo Clegg argumenta existir um distanciamento entre a vida quotidiana dos académicos e o que chama "centro" das universidades, ou seja, o modo como os decisores pensam as universidades e as unidades de investigação e as inserem em determinados roteiros temporais. Estes são expressos de diversas formas, incluindo na maneira como se publicitam certos projetos e/ou protocolos de colaboração e os quais são particularmente incisivos acerca desta orientação para o futuro (evidente no modo como a palavra surge integrada nessas diversas modalidades de discurso).

Felt, uma das autoras mais renomadas na área dos estudos da ciência e tecnologia nos tempos atuais, permite uma visualização bastante completa das transformações do tempo e das temporalidades nos contextos da ciência. A autora não aborda especificamente o trabalho ou a performance do cientista - a qual passa necessariamente pelo transporte de um discurso sobre o tempo e a temporalidade mas a temporalidade no próprio contexto da atividade de investigação na área da ciência e da tecnologia. Felt (2015) esclarece que o tempo e a temporalidade são dimensões centrais da participação em questões de ciência e tecnologia, além de permitirem perceber os enredos da ação política em ciência e tecnologia. Particularmente relevante é a abordagem que enceta sobre as figuras e imaginários 
temporais que presidem à definição de políticas e formulações discursiva na Europa a propósito da relação considerada causal e inequívoca entre futuro e ciência e tecnologia. A autora explícita, a partir de referencias centrais como Adam e Groves (2011), que a narrativa europeia para a inovação está centrada sobre "questões de tempo, timings, roadmaps, milestones, trajetórias, janelas de oportunidade e futuros a atingir". Quer dizer,

"A powerful European sociotechnical future is envisioned that will depend on both an ever increasing flow of technoscientif in innovations and a 'European public' supporting them (Felt, 2010). This vision fits well with the broader diagnoses that we live in a time characterized by a "breathless futurology" (Harrington et al., 2006) embedded in an "economy of techno scientific promises" (Felt et al., 2007); a time when "standing still means falling behind", when "acceleration becomes an economic imperative" (Adam and Groves, 2007), and when multiple "anticipatory regimes" (Adams et al., 2009) are put in place to assure the realization of the notyet. In these debates on remaking Europe through innovation, we perceive a multitude of temporal orders at work that appear to be largely taken for granted" (Felt, 2015, p.13).

Por outras palavras, há contexto atual, assim como justificação para politizar o tempo, como afirma Vostal (2013), tornando necessariamente um eixo de análise de negociação e reflexão da diversidade em contexto organizacional. Trata-se de um projeto que exige esforço considerável na superação das questões mais típicas relacionadas com as quantidades de tempo a alocar a cada tarefa, horários de trabalho, entre outros. É nesse sentido relevante considerar o que nos diz Muller. A autora, seguindo o alinhamento de Clegg (2010) e Felt (2015) mostra que a temporalidade na ciência e na academia estão atravessadas pelo domínio da antecipação que se reflete em carreiras hiper lineares e especializadas e formas de avaliação curricular demasiado centradas no trabalho acumulado, em prejuízo da qualidade dos projetos apresentados:

"Predictability of results and hence publication within a certain, foreseeable time span becomes a marker of an attractive postdoc project. Risk, in terms of less predictability and openness of possible results becomes problematic in a research culture, in which keeping up the relentless pace of publication is paramount. Epistemic risk needs to be avoided or at least tamed. Many postdocs employ the 
first strategy of choosing a rather safe project with somewhat predictable outcomes. Some postdocs, who speculate on a paper of particularly high impact (Science, Nature, Cell), attempt the latter: they work simultaneously on one safe and one high-risk project". (Muller, s/p).

Importa salientar que se trata de uma temporalidade gendarizada. Isto é, modelo de organização e de funcionamento que reflete, no sentido de Walvy (1997), o principio de regulação do capitalismo financeiro. Repegando as ideias de Adam acerca da pobreza epistemológica e valorativa da orientação baseada na temporalidade linear, a autora (Walby, 1997) esclarece que muitos dos efeitos perversos do crescimento económico e, portanto, do modelo de organização capitalista instalado, derivam da prevalência de princípios de orientação temporal alinhados na base da temporalidade acumulativa e linear, da extração do valor do tempo de trabalho humano.

Ainda como ponto último desta síntese acerca das temporalidades macro estruturais, retomemos Felt (2015). Com efeito, a sua análise contribui para o entendimento da estrutura e modos de aplicação das políticas para a ciência e tecnologia. Aponta, também, reflexões importantes em relação aos processos que decidem as prioridades em ciência. Felt (2015) mostra a saliência do tempo como objeto de estudo da política científica e tecnológica. Classifica-o como problema prático a enfrentar pela ciência, no que respeita à longevidade dos resultados, assim como ao tempo certo para estes serem disseminados e produzirem impactos. Considerando o tempo como sendo algo mais do que a sua medida quantificável e controlável através do relógio, calendário ou outros instrumentos, Felt considera existirem três inconsistências temporais às quais importa atender, no sentido da programação e implementação da política científica deliberativa.

Com efeito, a primeira dessas inconsistências, cuja classificação retoma de Giensen (2004 citado em Felt, 2015, p. 13) refere-se ao facto de, num processo que se deseja participativo, os sujeitos envolvidos serem portadores de preconceitos sobre a possibilidade de os outros entenderem as escalas de tempo em causa, isto é, há com frequência, considerações acerca da capacidade dos envolvidos estarem à altura do tempo presente que dificultam a participação. A segunda inconsistência diz respeito à perceção da simultaneidade: os participantes assumem comummente que os processos envolvendo ciência e tecnologia ocorrem em diversos locais a ritmos diferenciados, perspetivando a sua ação e contribuição com muita incerteza. A 
terceira fonte de inconsistência prende-se com a tensão entre momentos sincrónicos e assincrónicos do próprio processo participativo, sendo frequente ter posições diversas dos vários participantes, conforme o desenvolvimento do próprio processo participativo. Posições necessárias considerar e, de algum modo, gerir, de forma a atingir resultados.

Vostal (2013) usa as conceptualizações de vários dos autores citados, confirmando a tendência da aceleração do tempo na academia, no contexto britânico. O autor considera existir hoje o que chama "doutrina da excelência". Esta é um mecanismo de conformidade temporal, através do qual os próprios participantes ficam indiferentes ou acríticos, face à própria aceleração do tempo - na aceção do aumento de tarefas a realizar no mesmo espaço de tempo. Segundo Vostal (2013), esta naturalização da excelência e, portanto, da capacidade de adaptação e de resposta às exigências, provoca frustrações e diferenças no interior do próprio meio científico e académico. Trata-se de um efeito que surge evidenciado de forma distinta, conforme a atuação de outras variáveis, entre as quais as relacionadas com etnia, género, grau e posição hierárquica, ou mesmo vínculo contratual (Vostal, 2013, p.83).

Neste sentido, os efeitos das temporalidades macroestruturais e suas caraterísticas de aceleração e abstração são relativos. Propagam-se em direções e intensidades diversas, conforme o poder associado aos investigadores/cientistas (refletido na conjugação de efeitos idade-género-etnia-área e, potencialmente, classe social e capital social “académico"), às unidades de investigação (sob a forma de prestígio, avaliação montantes de financiamento), assim como às estruturas subsequentes, incluindo universidades/instituições de ensino e investigação e, eventualmente, países.

Como observamos, as análises de caráter estrutural põem questões centrais de ordem política e que importam tanto às agências e instâncias de governo nacionais, como supranacionais. Neste sentido, retemos como ideias centrais a existência de uma crítica acentuada à forma como as instituições de investigação e ensino estão identificadas com os processos de aceleração dos tempos em contexto institucional e quotidiano. E, igualmente, o elevado grau de coincidência entre estas formas de aceleração e a orientação para o futuro, gerando necessidade constante da experiência de antecipação, nos mais diversos níveis e planos. 


\section{O Tempo do(no) Processo de Investigação}

Duas ideias surgem evidenciadas nos estudos citados acerca do tempo na investigação: em primeiro lugar a ideia de que o da (na) investigação se faz maioritariamente em termos de desenvolvimento e conclusão de "projetos" que transportam uma temporalidade própria, sujeita a vários outros tempos. Os efeitos são, por vezes, incontornáveis e, mediante a abstração progressiva do tempo e sua avaliação, entram, frequentemente, em conflito entre si, devido às lógicas temporais e sequenciais próprias da investigação científica, seja qual for a área. Em segundo lugar, a ideia de que a investigação científica se constitui como uma atividade, cujo tempo de desenvolvimento resulta de uma intensa integração de vários outros tempos, incluindo os tempos próprios investigadores, incluindo pessoais e familiares.

Quer dizer, o tempo da e para a investigação resulta das interações e sociabilidades de várias ordens que se entrecruzam no universo do trabalho de planeamento e execução de projeto e cujas velocidades não obedecem, do ponto de vista do seus processos internos, a uma medida especifica. Esta ideia surge evidenciada por Noonan (2015) que, justamente, perspetiva o modo como a medição do tempo em investigação contém um elevado grau de artificialismo, quando focada sobre as quantidades de tempo idealizadas para cada atividade, descurando-se a dimensão psicossociológica da passagem do tempo.

Na essência, Noonan (2015) debate o lugar, o sentido e a pertinência do "tempopensamento". Este está, na sua perspetiva, em desuso e em declínio acentuado, face à progressiva penetração do capitalismo académico (Slaugther e Leslie, 1999). Por outras palavras, face à normalização "tempo - dinheiro", traduzido no facto de múltiplas atividades e múltiplos espaços-tempo de atuação desencadearem a “aceleração" do tempo. Por outro, o tempo-dinheiro, afirma o autor (Noonan, 2015, p.111) interfere com a unidade temporal da atividade humana, dividindo-a e parcelando-a em pequenas sequências, com o objetivo e a tornar mais produtiva. É, aliás, nesse sentido que Noonan considera estar aberto o caminho para a redução da liberdade académica.

O trabalho do cientista e do académico varia em termos de áreas científicas e, necessariamente, em termos de culturas organizacionais e modos de estruturação e organização interna às instituições em que se situam. Mas, de modo geral, tal como Noonan explicita, trata-se de uma atividade que passa por processos de transformação idênticos aos de outras atividades. Entre outras, a reconfiguração tecnológica que afeta 
as várias dimensões e esferas da própria atividade, quer no que se refere aos contextos espácio-temporais da atividade, quer no que respeita às novas potencialidades metodológicas que oferece. Acrescem a esta mudança nos processos de trabalho, as transformações na própria estrutura do tempo no contexto organizacional, cada vez mais conjugada com a implementação de plataformas digitais portadoras de temporalidades singulares.

Em causa está a transformação dos tempos e das temporalidades da investigação e do ensino, a qual traz mudanças significativas na forma como os processos relacionais necessários ao desenvolvimento da atividade tomam lugar. Noonan (2015) considera que as temporalidades são alimentadas pela tecnologia e estão ancoradas no principio do valor monetário do tempo. Além disso, atuam no sentido de tornar o tempo mais escasso e, progressivamente, menos autónomo para os investigadores. Quer dizer, passa-se para uma situação em que o tempo que demora a realização de uma atividade conta mais na valorização desta, do que a atividade em si, ou os seus fins ou fundamentos.

A observação dos planos de controlo da qualidade pedagógica, assim como os critérios de avaliação do desempenho organizacional e do docente e cientista justifica estas conclusões. No conjunto, evidenciam modos de proceder conformes a uma lógica de avaliação do tempo linear, fragmentada e abstrata que, de algum modo, se impõe como referencial na academia e na ciência, normalizando os processos de interação constituintes do próprio trabalho em ciência e ensino (Nonnan, 2015).

É preciso distinguir, como o dissemos antes, várias dimensões do tempo na academia e na investigação, pois, se por um lado, há o tempo da e para a investigação e o desenvolvimento da atividade e os modos de valorização e de experiência dos próprios investigadores e académicos, por outro, há o tempo da investigação em si, o tempo dos processos investigativos e, inclusivamente, dos resultados do trabalho científico e seus impactos. Numa linha inspirada em Marx, Noonan (2015) retoma outra questão central que se prende com os processos de desvalorização e de proletarização. Estes ocorrem no interior das atividades ligadas à produção e disseminação do conhecimento, incluindo a investigação científica. A informação comparativa escasseia, mas é possível adiantar que se trata de um processo que ocorre à escala global e ao qual se liga a própria mobilidade "forçada" dos investigadores e cientistas, sobretudo em inicio de carreira (Kehm, e Teichler, 2013; Fumasoli et al., 2015). 
De acordo com Noonan (2015) a atividade científica torna-se numa atividade normalizada segundo princípios que regulam qualquer outra atividade submetida à lógica do assalariamento. Esta abordagem assume a regulação da ciência e do ensino pelo capital, uma ideia moldada a partir da abordagem de Karl Marx (1997) sobre a génese do capital e a diferença entre trabalho produtivo e improdutivo. É nesta linha que Duarte (2003) esclarece ser a sociedade de conhecimento uma sociedade assente na proletarização do trabalho em ciência e ensino, respondendo a modos de fragmentação do tempo ajustados à rentabilização dos resultados no mercado. O autor considera que a sociedade de conhecimento acaba por dar uma excessiva centralidade à aquisição de conhecimentos, face á capacidade para mobilizá-los, implicando algum menosprezo pelos tempos das aprendizagens e o reforço das hierarquizações entre áreas de conhecimento.

\section{Método}

A reflexão que encetamos neste texto tem por base 103 entrevistas realizadas em diversos centros e universidades. Parte destas entrevistas (30) foi realizada no contexto de um outro trabalho realizado sobre o processo de doutoramento e pessoalmente (Araújo, 2005). Outra parte (63) refere-se a entrevistas realizadas também pessoalmente, no âmbito de um projeto sobre carreiras na investigação e mobilidade (Araújo e Fontes, 2013). As restantes (13) foram realizadas recentemente ou por via presencial ou através de uma plataforma eletrónica, no âmbito de um estudo que endereça especificamente as representações e usos do tempo na ciência e investigação e que ainda nos encontramos a realizar, procurando uma apreciação comparativa com outros países (Araújo, 2015). Este estudo envolve uma abordagem metodológica triangular, com recurso a técnicas diversas e, no caso especifico das entrevistas, privilegia os princípios da diversidade e da saturação da informação, baseando-se numa abordagem à população de investigadores que estão a trabalhar ao abrigo de um contrato, em universidades públicas.

Apesar de se assumir a existência de diferenças nas experiências e discursos sobre o tempo por parte de investigadores que acumulam, em simultâneo, tarefas docentes, esta fase da pesquisa privilegiou a integração das duas categoriais, de modo a melhor esclarecer sobre a transversalidade de algumas questões. Em fases seguintes, a análise da informação terá em conta a comparação entre grupos, considerando igualmente outras variáveis, incluindo a área científica e algumas caraterísticas relacionadas com as instituições de pertença. 
A conjugação da informação proveniente de diversas fontes comporta limitações, desde logo no que respeita à tipologia de pessoas envolvidas nos respetivos estudos. $\mathrm{O}$ facto de termos adotado por este caminho neste texto deve-se ao facto de este ter um caráter exploratório e, em certo sentido, pretender aferir a adequabilidade das abordagens teóricas existentes.

A informação documental, assim como os discursos recolhidos por via das entrevistas, adquirem um papel central neste projeto mais vasto de análise ao tempo e às temporalidades nos universos da ciência e do ensino superior (entre si, distintos no conteúdo e no modo de operacionalizar e normalizar o tempo e as durações). Uma das fases do projeto inclui a realização de um breve questionário, todavia, um dos desafios mais relevantes que enfrentamos prende-se com a recolha de informação através de observação direta, aliás, uma das fontes principais de informação, desde logo porque as questões que endereçamos como centrais no estudo são se tornam apreensíveis e tratáveis de forma completa através de questionamento direto e face a face.

É no contacto direto e na imersão no campo de estudo que o/a investigador/a se torna mais próximo/a e acede aos significados, contradições e ambiguidades das experiências, tal como vividas, no sentido da desconstrução das normas temporais que estruturam e constrangem a ação dos sujeitos. É nesse caminho que um sem número de notas tem sido registado ao longo de mais de dez anos nos mais diversos ambientes participados pela autora e tratados em conjunto com as restantes informações recolhidas de forma direta ou através de documentos e escritos vários.

Dada a natureza da informação recolhida e a necessidade de considerarmos nesta fase diversos momentos de recolha e tratamento de informação, focamo-nos ao longo deste texto exploratório sobre as principais vertentes de problematização do tempo dos(para) os cientistas docentes e não docentes, integrando nela a informação recolhida que se apresenta com valor heurístico para o esclarecimento das principais dimensões do tempo na academia e na ciência.

\section{Resultados e Discussão}

\section{Principais experiências do tempo e temporalidade}

Tal como procurámos evidenciar acima, apesar desta perspetiva acerca dos tempos dos processos e das culturas científicas e organizacionais, uma das dimensões mais estudada diz respeito à experiência do tempo e da temporalidade no contexto 
académico. Dissemos também que tais contextos estão marcados por uma profunda guerra semiótica dos tempos e das durações. Esta reflete-se na ansiedade pela publicação de resultados nas revistas científicas mais cotadas, na observação e controlo dos usos do tempo, assim como nas estratégias de separação e dedicação do tempo a tarefas administrativas, de docência e investigação. Ainda que referindo-se a uma categoria específica, Muller (2014, s/p), conclui que o que mais carateriza as narrativas dos cientistas pós doutorandos que entrevistou é a sensação de "estar permanentemente numa corrida competitiva que requer um ritmo cada vez mais acelerado, assim como um foco sobre o sucesso individual".

Considerando o efeito dos tempos mediáticos nos processos de legitimação institucional das organizações de investigação e de ensino (embora mais importantes nestas últimas), orientaremos a apresentação dos resultados pela abordagem de Ylijoki (2010, 2013) e de Hans (Ylijoki e Hans, 2003). Nestes trabalhos estão explicitadas as principais estruturas de tempo que atravessam a academia e a ciência e cuja validade tem sido demonstrada em investigações subsequentes. Ylijoki e Hans (2003) propõem que, apesar de investigadores terem uma relativamente elevada autonomia na organização do tempo, tendem, em geral, a perceber o tempo a partir do que considerem ser impositivo: prazos, horários, calendários de reuniões, entre outros. A este tempo as autoras chamam tempo "marcado" (scheduled time), embora considerem que tanto possa ser linear (o caráter do tempo no desenrolar de um plano de aulas ou projeto), como circular (o caráter do tempo que se impõe no acompanhamento de orientandos e ou outras atividades cuja conclusão exige continua reformulação). É o predomínio desta perspetiva sobre o tempo "marcado" que justifica que as narrativas dos próprios investigadores enfatizem, a preocupação com a "perda" e o "consumo de tempo".

Os nossos resultados são compatíveis com este enquadramento e reiteram os achados de Spurling (2015) que identifica como uma das dimensões principais de análise do tempo por parte dos académicos e cientistas a difícil coordenação e divisão de tempos, em particular quando acumulam tarefas de lecionação cujo carater temporal é mais previsível e disciplinado e urgente e tarefas de investigação, sujeitas a tempos de tipo mais flexível. Uma das pessoas que entrevistamos explicita a ambiguidade que atravessa esse tempo marcado, enfatizando a experiência da opacidade, assim como de uma autonomia aparente na administração do tempo: 
"Penso que olham para os docentes/investigadores como roldanas descartáveis; quando uma se parte (ou adoece), substitui-se. Até lá, sobrecarrega-se o que for preciso sem atender ao tempo real das tarefas atribuídas, ou à justiça na distribuição das tarefas entre todos os colegas. Os docentes/investigadores trabalham sem limite de tempo, na universidade e em casa, noites e fins de semana, sendo isso considerado normal".(E3)

Com efeito, observámos ao longo da sistematização e análise de informação que recolhemos, haver uma relação entre a experiência acentuada de falta de tempo (que já não é ausência de uma quantidade de tempo, mas a sua valorização psicológica traduzida na angústia da possibilidade de produzir mais ou outros resultados, em particular na investigação/publicação), e a enfase dada à sobreposição de tarefas e ao "consumo de tempo" por parte das atividades de ensino e à "perda de tempo" em tarefas administrativas e/ou de gestão e de prova. Citemos, no propósito de evidenciar a importância da experiência e internalização da antecipação, um dos entrevistados que considera existir um "desequilíbrio profundo" sobre as exigências e o tempo, muito embora não se trate de uma articulação passível de qualquer administração meramente quantitativa:

"Há desequilíbrio profundo entre as tarefas propostas e esperadas e o tempo efetivamente existente para as realizar. Considero também que as tarefas de docência exigem muito tempo e dedicação e que, posteriormente, não são devidamente valorizadas na avaliação de desempenho (...) o meu trabalho (enquanto docente, investigador e responsável por cargos de gestão e interação com a sociedade) avolumou-se de tal ordem que não consigo arranjar tempo para cuidar de mim, das minhas refeições, da minha saúde, da minha casa, da minha família, de nada. Sobrevivo em todas essas áreas para que o trabalho corra bem". (E3)

$\mathrm{O}$ excerto é exemplificativo de um padrão típico de experiência e reflexividade sobre a experiencia do tempo em territórios académicos marcado pela tensão permanente entre tais modos "antecipados" de valorização do tempo. Para melhor compreensão, consideremos, a este respeito, os procedimentos de avaliação de desempenho que inscrevem uma temporalidade não de todo compatível com as metodologias estipuladas no ECDU - Estatuto da carreira Docente em Portugal. Os primeiros pautam-se por um conjunto de representações que se associam e reproduzem a concetualização mercadológica da ciência e do ensino inclusivamente 
vertida sobre os modos de aceleração da disseminação dos resultados científicos (Clegg, 2010), produzindo uma temporalidade de carreira de caráter mais coletivo e circular.

O EDCU - que funcionaria como o "quadro temporal" principal de referência para a (auto) avaliação dos próprios docentes e investigadores - reflete um princípio de orientação temporal de carreira de moldes muito mais lineares e individualizantes, centrados sobre as dimensões da investigação. Tomadas em perspetiva, ambas se constituem como temporalidades complementares embora conflituantes, marcadas pela ambiguidade. No momento atual, e, em particular, para Portugal e no contexto das mutações das próprias carreiras na investigação e no ensino superior, constata-se serem realidades opacas, pouco explicitadas e debatidas, inclusivamente sob o ponto de vista do trabalho e dos "recursos humanos" em ciência.

Retomando o excerto que apresentámos acima, verifica-se que esta posição acerca do tempo dos outros e a forma como tempo é preenchido e usado é um traço muito evidente nas interações quotidianas em contexto de trabalho. Todavia, ganham mais expressão no contexto das atividades de docência ou investigação científica, tratandose de atividades bastante dependentes do reconhecimento dos pares. Este materializase, grandemente, através do "re-conhecimento" do tempo apresentado sob a forma de uma performance (ou estilização) constante do próprio investigador sobre a importância do seu próprio tempo. Esta atitude perfomativa em relação ao tempo "usado", "gasto", "dedicado", “empregue”, "perdido", "roubado" é talvez uma das formas mais implícitas mas interessantes dos processos de construção e afirmação identitária dos cientistas e investigadores. Observa-se em vários contextos de interação, tal como tivemos oportunidade de registar ao longo do nosso percurso etnográfico. Toma forma através de discursos extensamente descritivos e justificativos das atividades que estão em desenvolvimento ("o que eu tenho para fazer").

Relativamente à definição e avaliação do tempo próprio - nomeadamente atendendo ao ensino e investigação - os participantes no estudo apresentam muita dificuldade em defini-lo e posicionar-se em relação ao tempo de que dispõem, o que evidencia a natureza tomada como garantida dos regimes de tempo, por mais convencionais e artificiais que estes sejam, isto é, sejam criados através de regulações e de procedimentos típicos das instituições e por vezes em resultado de imitação de outros contextos 
As questões levantadas sobre a aceleração do tempo na ciência e investigação constituem hoje um foco das interações quotidianas dos cientistas, particularmente quando acumulam funções de docência e de administração/gestão. $O$ excerto que transcrevems a seguir traduz a presença, igualmente ambivalente, do tempo "desejado" e do tempo "possível":

“O meu tempo é cada vez mais escasso para desenvolver as atividades de ensino e, sobretudo, de investigação. É necessária uma enorme disciplina e planificação do trabalho, até porque, além dessas atividades, há muitas outras. No meu caso, procuro conciliar, sempre que possível, as atividades de ensino e de investigação, mas haverá áreas em que isso pode ser difícil de fazer. De uma forma geral, a ideia é de falta de tempo, permanentemente, sobretudo para quem quer desenvolver uma investigação séria, efetuar novas leituras e dar a devida atenção aos alunos e às orientações de dissertações de mestrado e teses de doutoramento". (E9)

Nesta sequência, mencionemos o tempo pessoal que surge normalmente perspetivado de forma negativa pelos entrevistados, por ficar na dependência do tempo de trabalho e se tornar vulnerável à transferibilidade de tempos. Esta conclusão subscreve o entendimento de Ylijoki e Hans (2003) que afirmam serem as narrativas do tempo pessoal normalmente apresentadas de forma negativa, devido à experiência da falta de tempo para outras atividades e cuidados, sobretudo familiares.

Ylijoki e Hans (2003) referem-se também ao "tempo sem tempo" (tímeles time), propondo que se trata do tempo da investigação científica propriamente dita, da leitura, reflexão, do teste, da descoberta. As autoras assinalam que os investigadores (que acumulam funções de docência, ou não) normalmente se referem a este tempo como um "ideal”, um tempo que não está na sua posse diária ou que seja realizável no plano diário. Tal como dissemos acima e constitui um dos focos deste texto, trata-se de um tempo hoje caraterizado, no contexto da academia e da investigação (e particularmente quando falamos de investigadores a tempo inteiro mas com funções de coordenação de projetos) pela contínua interferência da temporalidade avaliativa. Tal como propõem estas autoras (p.66), acaba por ser o tempo ao qual é atribuído mais valor, desde logo porque está associado a uma avaliação e/ou reconhecimento.

Ylijoki e Hans (2003) descrevem e analisam ainda o tempo "constrito", o qual traduz a perspetiva temporal caraterizada pela fragilidade dos contratos de trabalho e pela incerteza associada: 
"Faço constantemente diretas para submeter projetos, escrever artigos corrigir monografias e relatórios e teses. Perco tempos infindáveis com burocracias das encomendas nos SIG e no stresse das faturas. Faço tudo, o meu trabalho e o dos outros. Não tenho filhos, nunca tive tempo. Não tenho um confortável lugar de professor, o meu tempo acabará daqui as uns anos...e até lá sei que não terei tempo de procurar emprego. E quando o perder ninguém terá tempo para me dar. Penso muitas vezes em que vida é esta. Tive 15 dias de férias e senti que estava a perder tempo". (E2)

O tempo constrito, referente ao tempo de contrato e à estabilidade deste configura um dos textos mais estruturantes dos quotidianos dos investigadores. Nesse sentido, e na perspetiva das autoras, a situação é paradoxal. Por um lado, há a aceitação do bem comum como a finalidade principal da ciência, assim entendida numa escala de tempo longo. Mas, por outro, verifica-se o encurtamento dos contratos e dos vínculos dos investigadores, particularmente mais jovens, com as instituições, o que traz dificuldades à realização dessa finalidade. Apesar de o "tempo- contrato" não aparecer ainda evidenciado nas entrevistas que recolhemos especificamente para este projeto, algumas das afirmações das pessoas entrevistadas manifestam esta ideia de que " as instituições estão a perder fatores de qualidade que a curto e longo prazo se verá” (E8).

Frisemos, a propósito, um outro estudo de Ylijoki (2010) no qual a investigadora conclui existirem perspetivas diferenciadas no modo de entendimento do futuro por parte destes investigadores: o "foco sobre o presente", a "experimentação de várias alternativas" e, por fim, a "linearização e disciplina temporal". Mais do que propor a tipologia, a autora salienta como efeitos negativos a qualidade da investigação e a saúde mental e física dos investigadores. É neste sentido que propõe o repensar sobre as articulações temporais nas instituições de ensino e de investigação.

$\mathrm{O}$ efeito da metamorfose do tempo e o seu reflexo na motivação dos cientistas ainda está por aprofundar, tendo em conta outras variáveis. Falamos, por exemplo, dos modos de organização material da investigação nas próprias organizações (incluindo apoio a funções científicas e o escrutínio entre tarefas a executar pelos cientistas e tarefas a desenvolver por técnicos).

“As instituições e serviços cumprem instruções sem qualquer visão crítica e com muito limitada autonomia. Exigem, porque sim; implementam, porque tem que ser; desenvolvem, porque almejam uma qualquer certificação de 'qualidade'. O tempo 
do outro deixou de ter limites e fronteiras, uma vez que o funcionário está em permanente estado de alerta e prevenção, recebe mensagens de dia e de noite, à semana e ao fim-de-semana (...) As vezes parece que os investigadores estão ao serviço dos serviços burocráticos, e deveria ser ao contrário”. (E2)

Ademais, tal como Vostal esclarece, as experiências fenomenológicas da aceleração são necessariamente diversas. Quer dizer, da mesma fora que o posicionamento critico face à aceleração do tempo académico e da ciência foca a relação negativa dessa aceleração com a existência de intervalo de tempo para pensar, refletir e ponderar as questões de investigação, desenvolver os projetos e proceder à realização das tarefas, deve considerar-se que a mesma escassez do tempo possa ter efeitos motivadores no desenvolvimento de todo esse roteiro de tarefas, mais ou menos explicitas e sobretudo, não lineares (Vostal, 2013, 85 e ss).

Esta ideia é explicável na base dos próprios pressupostos da psicologia do tempo que analisa o modo como as perceções da duração são afetadas pelo conhecimento e antecipação do término da ação. A pressão temporal, traduzida em prazos, indicadores de produtividade e outros marcadores temporais, é tida como influente, de forma positiva, sobre a própria "qualidade" do tempo, desde de que e sempre que permitam uma melhor visualização do resultado final por parte dos sujeitos, ao qual corresponderá um nível de satisfação mais elevado, na vida, em geral. Os tempos de burnout e de depressão, característicos da profissão na ciência e investigação corresponderão, nesse sentido, beneficiam da regulação do tempo. Por outras palavras, há contexto atual, assim como justificação para politizar o tempo, como afirma Vostal (2013), tornando necessariamente um eixo de análise de negociação e reflexão da diversidade em contexto organizacional. Trata-se de um projeto que exige esforço considerável na superação das questões mais típicas relacionadas com as quantidades de tempo a alocar a cada tarefa, horários de trabalho, entre outros.

Deste ponto de vista, a análise do tempo da e para a ciência requer uma problemática que assenta no principio da necessária dialética entre tempos fortes e fracos, entre tempos acelerados e tempos lentos, tempos condicionados e tempos autónomos. Esta observação apresenta-se como essencial na perspetiva dos estudos organizacionais e, principalmente, na perspetiva da administração e gestão da ciência e da tecnologia na atualidade e nos diversos contextos organizacionais, designadamente dos centros de investigação. Apresenta-se igualmente necessária em 
contexto de investigação sociológica sobre as perceções e vivências dos próprios investigadores.

Entendidas como resultado de diversas interações com os vários ambientes onde a ação dos sujeitos se desencadeia, tais perceções (caraterísticas e modos de construção) são extremamente importantes para compreender os modos de experiência temporal dos sujeitos, inclusivamente as formas mais ou menos cooperantes e ou adaptativas à aceleração ou desaceleração do tempo. Com efeito, Ulferts e outros (2016) usam esta problematização, demonstrando ser o aumento de atribuições (que surge de forma formal ou opaca e informalmente) o principal motivo da perceção da aceleração do tempo por parte dos trabalhadores. Entre outros aspetos, os autores (Ulferts et al., 2016) denunciam o facto de a aceleração propiciada pelo desenvolvimento tecnológico não favorecer a libertação de tempo, mas justamente, aumento da sua densidade, com a inclusão de mais atribuições. Trata-se de um quadro genérico de interpretação transportável para o contexto da academia e da ciência.

As implicações dos tempos tecnológicos nos processos de trabalho e, principalmente, a sua tendência para a estandardização e discricionariedade constituem focos de análise teórica e empírica no contexto das atividades profissionais criativas e relacionadas com o tratamento e disseminação de informação. Existem múltiplas dimensões a explorar em relação a estas mudanças espácio-temporais associadas às tecnologias. Falamos desde mudanças dos lugares propriamente ditos para executar as atividades, até justamente, à quantidade de exigências que podem circular por esse meio.

As tecnologias digitais são consideradas hoje como meios essenciais do trabalho na área da academia e da ciência porque potenciam, não só outros ambientes de trabalho - facilitando a falta de logística, por exemplo, nos espaços físicos dos centros de investigação e de ensino - como também potenciam o aumento de interação e de cooperação ou trabalho em rede com investigadores das mesmas áreas, mas que vivem e ou trabalham em espaços geográficos distintos. O certo é que, apesar de se tratar de processo de mudança globais, que implicam estruturas espaciais complexas e amplas que desencadeiam modos operandi compatíveis com a construção e manutenção da chamada big data, os sujeitos encontram estratégias diversas no quotidiano que os auxiliam no contorno das suas funcionalidades, incluindo a produção de discursos que desconstroem as suas motivações. 
Algumas destas estratégias, não acessíveis a todos, por dependerem das margens de poder, traduzem-se em formas de resistência ou de afastamento. Vários dos investigadores que entrevistámos, por exemplo, contam fazerem "blackout" às tecnologias e aos pedidos endereçados eletronicamente, evitando as redes sociais eletrónicas, reagindo ao que consideram ser "kafkiano" no processo de preenchimento de formulários eletrónicos e outras plataformas classificadas como "consumidoras de tempo", considerando ser "ridícula a anergia que gastamos a preencher um relatório missão". Alguns destes entrevistados são até críticos severos dos usos que outros colegas fazem das tecnologias em virtude do mesmo motivo: consideram-nos meios consumidores de tempo e fonte de dispersão. Esta modalidade de resistência e de recusa, particularmente notada a respeito do trabalho administrativo e de controlo (ou de accountability) convive, no entanto, com a modalidade de aceitação e de valorização da temporalidade tecnológica e o modo como cria novas possibilidades ao trabalho em ciência, não só reduzindo o tempo gasto em certas tarefas e operações, como permitindo maior capacidade de armazenamento e colaboração à distância.

\section{Tempo Emergente - Tempo Mediático e Cerimonial}

Muller (2914) reflete sobre o movimento de "desaceleração da academia" /Slow University initiative), assinalando-o como como forma de resistência ativa, face à reprodução de um tipo e temporalidade que assenta no "empreendedorismo contínuo do self" (s/p). Há várias formas de interpretar este tipo de desaceleração de ritmos. Importa salientar que se verificam formas diversas de resistência e de estratégia por parte dos atores nos universos organizacionais concretos. Também se registam formas diversas de institucionalização de espaços-tempos de repouso/desaceleração. Seria necessário, a este respeito, percorrer uma extensa literatura acerca dos modos como os sujeitos sociais encontram formas de escape às temporalidades abstratas e potencialmente mais disruptivas dos seus quotidianos, valorizando, entre outras, a procura de ritmos contrários, ou em oposição aos mesmos.

Não cabendo na extensão nem no propósito do texto, centraremos a atenção sobre os momentos/intervalos produzidos pelas próprias instituições - as mesmas que asseguram as rédeas de uma temporalidade controlada e orientada pelos princípios do tempo - dinheiro- caraterizados pelo efeito de "abrandamento" do tempo. Um efeito deveras paradoxal na própria institucionalização do tempo moderno identificado em 
diversas terminologias temporalmente linearizantes, como "desenvolvimento inteligente": no mesmo momento em que as universidades e unidades de investigação - instituições que conformam maioritariamente o espaço-tempo da investigação sobre os quais temos vindo a falar - se investem de um tempo acelerado, medível, digital e di-ferido; contemplam intervalos que, sendo de desaceleração, mimetizam tempos míticos passados, reificando algumas das suas caraterísticas. Os mitos e as cerimónias - expressas pelos inúmeros momentos de celebração, comemoração e entronização de reitorias, direções, presidências, cursos, etc. que se sedimentam hoje como integrantes dos processos de condução organizacional nas instituições de investigação e ensino e sempre invocativas de um passado, por vezes refletido nos espaços escolhidos, destilam hoje momentos de intervalo propícios ao tempo lento.

São momentos que alimentam, no roteiro da aceleração do tempo da vida organizacional e individual, a própria legitimação junto da comunidade ativando de forma nem sempre harmónica, vários mecanismos de visibilidade dessas instituições, junto da comunidade. Os média, na sua oferta multidimensional de escalas temporais, apresentam-se como eixos de constituição dos projetos de identidade das instituições, tal como dos próprios investigadores. Os tempos mediáticos são, assim, outros tipos de tempos que influem sobre o tempo macroestrutural das organizações que lidam com a produção e disseminação de conhecimento, basicamente no sentido da geração de maior constrangimento temporal sobre os tempos da investigação científica, ou tempos do projeto de investigação. Mas também podemos relacioná-los com as experiências de vida dos próprios atores, em virtude de o próprio debate e controvérsia sobre o tempo (nas diversas perspetivas, como propomos acima), acontecer no espaço-tempo mediático, igualmente a diversas escalas. A mais reveladora (assim se subentendendo a dificuldade dos cientistas e académicos se projetarem no espaço do debate político) é a escala do tempo online, ao nível das redes e outras formas de exercício de reflexividade. Trata-se de um espaço onde vão aparecendo, embora de forma não sistematizada, algumas interações alusivas, não propriamente à experiência quotidiana do tempo, mas sobretudo aos tempos de contrato e suas formas de regulação. Uma análise mais detalhada e aprofundada seria necessária para perceber como o espaço-tempo online se propicia a ser um espaço de participação pública no debate sobre o tempo na ciência e academia. 


\section{Conclusão}

O objetivo deste texto consistiu em mostrar algumas das principais perspetivas temporais prevalecentes na academia, usando, para o efeito, informação recolhida no contexto português. No decurso da apresentação mostramos existir bastante correspondência entre os resultados atingidos por autores que desenvolveram investigação noutros países e os resultados que obtivemos. Dada a limitação da nossa pesquisa, não é possível classificar de forma específica as modalidades de experiência do tempo por parte dos cientistas e académicos, em geral. Todavia, foi possível demonstrar o interesse do assunto, nas suas múltiplas vertentes, assim como a pertinência dos quadros analíticos apresentados pelos autores dos estudos consultados. Inclusivamente, são bastante coincidentes com os resultados publicados num relatório de 2015, por Clarke, versando sobre as condições e ambientes de trabalho no ensino superior europeu. Neste relatório, entre outras informações, veicula-se o facto de o tempo não ser objeto de reflexão por parte das instituições e, em simultâneo, haver diversos problemas de motivação e de satisfação relacionados com a sua valorização ambígua. Ficam brevemente explicitados, entre outras, os efeitos do declínio de financiamento a projetos e ao trabalho dos investigadores, principalmente por via da proliferação de contratos precários; assim como a degradação das condições de trabalho, justamente ao nível dos investigadores com menos proteção contratual (Clarke, 2015, pp. 6-10).

Importa precisar que o relatório, baseado num levantamento de dados envolvendo questionário e entrevista, mostra, ainda, algumas particularidades no que respeita ao facto de as alterações introduzidas pelo "modelo de Bolonha", aliadas às condições culturais atuais, terem aumentado a dedicação de tempo a atividades pedagógicas e letivas, com maior envolvimento dos professores em diversos procedimentos administrativos envolvendo os alunos. Estas mutações, não sendo sempre ajustadas de forma equitativa (por exemplo, através de modelos de avaliação), podem estar na origem, não só de desmotivação, como de desorganização interna nas instituições, a diversos níveis.

Deixando perceber a reflexividade sobre o tempo e a intervenção sobre o tempo como um elemento central da gestão do conhecimento, em geral, os nossos resultados indicam existirem algumas tipologias singulares de tempo por parte dos cientistas e académicos, acumulando ou não funções de ensino em instituições como 
universidades e institutos politécnicos. Apesar de haver uma grande convergência de opiniões relativamente ao facto de o tempo estar nestes contextos em contínua "aceleração" (no sentido do aumento de atividades não previstas, emocionais, de preparação, de concurso), identificam-se estratégias diversas de coping que incluem tanto a experiência persistente do tempo antecipado; como estratégias de resistência e de recusa de tempos considerados menos válidos (por norma, aparecem referenciadas as atividades de administração e gestão, mas a sua valorização dependente também dos cargos e do reconhecimento destes. O mesmo acontecendo com as atividades de tutoria e de orientação). A estas discrepâncias na experiência do tempo, somam-se as variações na forma como as instituições regulam e administram as questões do tempo, nos diversos níveis, incluindo o da preparação e proposição de projetos a fontes financiadoras.

Fica mais claro, neste sentido, que o tempo deva ser pensado enquanto processo e enquanto relação. Com efeito, as considerações feitas acima são válidas para o contexto global dos tempos e das temporalidades, mas uma análise mais detalhada seria necessária no sentido de precisar os efeitos desta caraterística relacional do tempo e a qual pode explicar o facto de a ciência e investigação apresentarem modalidades diversas de autonomia e opressão do tempo, conforme os níveis hierárquicos e posições ocupadas pelos sujeitos nas diversas hierarquias (materiais e valorativas e /ou simbólicas) que as caraterizam. A organização institucional do tempo - não imediatamente detetável através das técnicas de entrevista ou inquérito por questionário- desempenha aí um papel também relevante. Além do efeito das culturas organizacionais e modos de colaboração e a forma como estas vinculam e tecem articulados temporais nos contextos empíricos de ação diária, é preciso contar com a relevância do grau académico/área científica e do género (Bentley, 2011), embora esta variável não seja objeto de análise neste texto.

Finalmente, o texto tinha como propósito deixar algumas contribuições da análise do tempo para a política científica, considerando esta como uma das estruturas principais de definição dos tempos em contexto organizacional e individual. Alguns autores (Macleod e Haygarth, 2008) argumentam em favor da institucionalização de uma paradigma de ciência integrada, inclusiva do ponto de vista científico, territorial e étnico, propondo a necessidade de as políticas para a ciência estarem alinhadas com várias escalas temporais. 
Assim, mais do que a diversidade de opiniões e formas de entender e atribuir valor às quantidades de tempo de cada atividade ou conjunto de atividades, a reflexão elaborada permite salientar, além da crítica aos regimes de tempo, a relevância em politizar o tempo e essas diversas escalas, reduzindo a sobreposição e o conflito entre escalas. Um projeto que se faz mediante o desenho e implementação de políticas efetivas, nomeadamente na área do trabalho docente e de investigação propriamente ditos, das carreiras, da avaliação, assim como implementação de programas. Torna-se importante a revisão da classificação do trabalho académico e de investigação científica à luz das transformações operadas pelo crescente uso do digital. Este não só afeta a delimitação entre trabalho e não trabalho, como também favorece o entendimento do trabalho realizado no tempo livre como atividade de lazer - uma ideia desenvolvida por Funchs (2013). Acrescentamos, como ponto final, o facto de se ter tornado evidente a forma como o tempo e a temporalidade constituem hoje elementos singulares na composição identitária dos investigadores, adquirindo um caráter performativo e classificativo, quer dizer, narrar e descrever o tempo constituise como forma poderosa de apresentação de si.

\section{Referências}

Adam, Barbara e Groves, Chris (2011), "Futures Tended: Care and Future-Oriented Responsibility", Bulletin of Science, Technology \& Society, 31 (1): 17-27.

Ait ali, Nawel e Rouch, Jean-Pierre (2015), “Le «je suis débordé» de l'enseignantchercheur“, Temporalités, 18. Retirado de http://temporalites.revues.org/2632.

Araújo, Emília (2005), O doutoramento: a odisseia de uma fase da vida, Lisboa, Colibri.

Araújo, Emília (2015), “O Tempo dos(para) os docentes e pesquisadores numa perspetiva do gênero", Artemis, 20: 39-56

Araújo, Emília e Ferreira, Filipe (2013), "A "Fuga de cérebros", um discurso multidimensional", in Emília Araújo, Margarida Fontes e Sofia Bento (Eds), Para Um Debate Sobre A Mobilidade e "Fuga de Cérebros", Braga, Centro de Estudos de Comunicação e Sociedade, Universidade do Minho (58 - 82).

Clarke, Mary (2015), Creating a Supportative Working Environment in European Higher Education, Education International Institute. Retirado de https://issuu.com/educationinternational/docs/highereducation. 
Clegg, Sue (2010), "Time future - the dominant discourse of higher education", Time \& Society, 19 (3): 345-364.

Felt, Ulrike (2015), The temporal choreographies of participation: Thinking innovation and society from a time-sensitive perspective, Pre-print, Departamento de Estudos de Ciência e Tecnologia, Universidade de Viena. Retirado de http://sts.univie.ac.at/publications

Fuchs, Christian (2013), "Class and exploitation on the Internet", in Trebor Scholz (Ed.) The Internet as Playground and Factory, New York, Routledge (211-224). Retirado de http://fuchs.uti.at/wp-content/CFdigitallabor.pdf

Fumasoli, Tatiana, Goastellec, Gaële e Kehm, Barbara (2015), The changing academy - the changing academic profession in international comparative perspective, Springer.

Harvey, David (1996), Condição pós-moderna: uma pesquisa sobre as origens da mudança cultural, São Paulo, Loyola.

Kehm, Barbara e Teichler Ulrich (2013), The Academic Profession in Europe: New Tasks and New Challenges, Neteherlands, Springer.

Macleod, C. J. A.; Blackstock, K. L. Haygarth, P. M. (2008), "Mechanisms to improve integrative research at the science-policy interface for sustainable catchment management", Ecology and Society, 13 (2). Retirado de http://www.ecologyandsociety.org/vol13/iss2/art48/-

Marx, Karl (1997), O capital: O processo de produção do capital, Lisboa, Edições Avante.

Menzies, Heather e Newson, Janice (2007), 'No time to think: Academics' life in the globally wired university", Time \& Society, 16 (1): 83-98.

Menzies, Heather e Newson, Janice (2008), “Time, stress and intellectual engagement in academic work: Exploring gender difference", Gender, Work and Organization, 15 (5): 504-522.

Muller, Ruth (2014), "Racing for What? Anticipation and Acceleration in the Work and Career Practices of Academic Life Science Postdocs", Qualitative Social $\begin{array}{llll}\text { Research, } & 15 & \text { (3). Retirado de http://www.qualitative- }\end{array}$ research.net/index.php/fqs/article/view/2245/3726

Noonan, Jeff (2015), “Thought-time, Money-time and the conditions of free academic labour", Time \& Society, 24 (1): 109-128. 
Rosa, Hartmut (2010), Alienation and acceleration: towards a critical theory of latemodern temporality, Malmo, NSU Press.

Slaugther, Sheila e Leslie, Larry (1999), Academic capitalism: Politics, policies, and the entrepreneurial university, Baltimore, John Hopkins university Press.

Smith, Simon (2015), "Multiple temporalities of knowing in academic research", Social Science Information, 54 (2): 149-176.

Spurling, Nicola (2015), "Differential experiences of time in academic work: How qualities of time are made in practice", Time \& Society, 24 (3): 367-389.

Ulferts, Heike, Korunkat, Chirstian e Kubicek, Bettina (2013), “Acceleration in working life: An empirical test of a sociological framework", Time \& Society, 22 (2): 161-185.

Vostal, Filip (2015). "Academic life in the fast lane: The experience of time and speed in British academia", Time \& Society, 24, (1): 71-95.

Walby, Silvia (1997), Gender Transformations, Londres, Routlege.

Winslow, Sarah (2010), "Gender inequality and time allocations among academic faculty", Gender \& Society, 24, (6): 769-793.

Ylijoki, Oili-Helena (2010),'Future orientation in episodic labour: Short-term academics as a case in point", Time \& Society, 19 (3): 365-386.

Ylijoki, Oili-Helena (2013), "Boundary-work between work and life in the high-speed university", Studies in Higher Education, 38, (2): 242 -255.

Ylijoki, Oili-Helena e Hans, Mäntylä (2003), "Conflicting time perspectives in academic work", Time \& Society, 12 (1); 55-78.

Data de submissão: 15/06/2016 | Data de aceitação: 19/12/2016 